Original Research Paper

\title{
The Effects of Cement Kiln Dust on the Soil Electrical Resistivity
}

\author{
Hamid Ranjkesh Adarmanabadi, Arezou Rasti and Mehrdad Razavi \\ Department of Mineral Engineering, New Mexico Institute of Mining and Technology, Socorro, United States
}

\author{
Article history \\ Received: 01-01-2021 \\ Revised: 11-01-2021 \\ Accepted: 14-01-2021 \\ Corresponding Author: \\ Hamid Ranjkesh \\ Adarmanabadi \\ Department of Mineral \\ Engineering, New Mexico \\ Institute of Mining and \\ Technology, Socorro, United \\ States \\ Email: hamid.ranjkesh@student.nmt.edu
}

\begin{abstract}
Electrical resistivity is a non-destructive, cost-effective and sensitive method to evaluate soil's physical and chemical properties. Electrical resistivity has been used widely in surface and subsurface exploration. The electrical resistivity is directly related to the subsurface geotechnical and geothermal properties like porosity, temperature, salinity and water content. Recently uses of waste material as an additive to improve the soil engineering properties are growing because of their costeffectiveness. Cement Kiln Dust (CKD) is a waste material of the cement manufacturing process. CKD is widely used as an additive material in ground improvement to improve soil's geotechnical properties. This study is mainly focused on the effect of CKD on the electrical resistivity properties of the soil. In this study, the electrical resistivity of a natural soil slope treated with CKD and a test model in the laboratory was investigated. Besides, the effects of $\mathrm{CKD}$ on soil $\mathrm{pH}$ and electrical resistivity were studied by performing a series of tests to predict the soil's corrosivity potential. The soil was treated with $0,5,10$ and $15 \%$ of CKD and the electrical resistivity of the soil was measured at different water contents, porosities and curing times. The results indicate that the soil's electrical resistivity increases by increasing the CKD content and curing time. Additionally, an increase in water content or porosity decreases the electrical resistivity of CKD treated soil. Furthermore, the electrical resistivity measurement is a practical method to determine the stabilized soil's geotechnical and geomechanical properties.
\end{abstract}

Keywords: Cement Kiln Dust (CKD), Electrical Resistivity, Soil pH, Soil Corrosion, Soil Stabilization

\section{Introduction}

Soil electrical resistivity measurements determine how much the soil's resistance is in the flow of electricity. The soil resistivity patterns in different depths provide the subsurface heterogeneities and geotechnical properties (Samouëlian et al., 2005). Many factors affect the soil resistivity, including particle shape and size, moisture content, temperature, degree of saturation, porosity and chemical content. Due to these parameters' effect, the soil electrical resistivity has an extensive range and changes widely throughout the world and seasonally (Abu-Hassanein et al., 1996). The purpose of soil electrical resistivity measurement is to obtain geophysical and geotechnical data such as depth to bedrock, ore location, soil hydraulic conductivity, soil corrosiveness and its effects on the design of a grounding system (Kalinski and Kelly, 1993).
Recently waste materials are widely used for soil improvement (Rouhanifar et al., 2020). Cement kiln dust is a waste material generated from the cement manufacturing process. This by-product of cement production is fine, powdery and alkaline and has wide application for many fields, especially in civil engineering works (Baghdadi et al., 1995). Soil stabilization with CKD increases the soil strength, soil $\mathrm{pH}$ and optimum water content and decreases the permeability and plasticity index (Ghazvinian and Razavi, 2010; Faramarzi et al., 2016; Ranjkesh Adarmanabadi et al., 2020). Electrical resistivity is an effective method to assess the physicochemical properties of natural and engineered soils (Cai et al., 2015). Some investigations indicate that the soil's electrical resistivity can determine the soil characterization and mechanical properties (Damasceno et al., 2009; Rinaldi and Cuestas, 2002). 
Komine (1997) conducted an experimental study on the chemical grouted sand to evaluate the soil geotechnical properties using the electrical resistivity method. The results indicate that grouted sand's electrical resistivity correlates with water content, void ratio and particle size distribution (Komine, 1997). Liu et al. (2008) investigated the soil-cement admixture's electrical resistivity by considering the curing time and water content ratio. The results showed by increasing the quantity of cement and curing time, the electrical resistivity of soil risen. As the water content and soil degree of saturation increased, the electrical resistivity was reduced (Liu et al., 2008).

Chen et al. (2011) conducted a study to determine cement-stabilized lead-contaminated soils' geotechnical properties using electrical resistivity measurements. In this study, the soil was contaminated with various lead concentrations and treated in three Portland cement content levels. The results showed that soil's electrical resistivity was enhanced by increasing the amount of cement and time and it declined by increasing the lead concentration (Chen et al., 2011). Zhang et al. (2012) examined the electrical resistivity and unconfined compression strength of cement-treated soil. For this purpose, the effect of cement content, porosity and time on the electrical resistivity of cement-treated soil were evaluated. This investigation proved that the cement content and curing time are meaningful parameters to increase soil's electrical resistivity (Zhang et al., 2012). An experimental study reviewed the effect of heavy metal concentration on stabilized soil's electrical resistivity behavior with cement and fly ash. For this investigation, $\mathrm{Pb}, \mathrm{Zn}$ and $\mathrm{Cr}$ were selected to prepare contaminated soil because of their high solubility. The two-electrode probe method was applied to measure the electrical resistivity of samples in curing time. The results demonstrated that electrical resistivity was raised by increasing curing time. On the other hand, by increasing heavy metal concentration, the soil electrical resistivity was reduced (Liu et al., 2019).

Electrical resistivity is one of the most significant geophysical methods to investigate stabilized soil properties (Tabbagh et al., 2000). The electrical resistivity method was used in an experimental study to determine the fly ash's hydration process. Different amounts of fly ash were added to the Portland cement paste to monitor the electrical resistivity behavior. The results showed that the electrical resistivity increased as fly ash contents increased (Liao et al., 2019).

This investigation aims to determine the effect of cement kiln dust content, water content, porosity and curing time on stabilized soil's electrical resistivity. Besides, the relation between the unconfined compression strength and soil electrical resistivity was examined. For this purpose, a natural slope treated with different amounts of CKD was chosen to perform the field test. The test was simulated to evaluate the soil electrical resistivity with the same structure by considering the different water content and curing time in the laboratory.

\section{Methodology}

\section{Field Electrical Resistivity Measurement}

For this investigation, a natural slope stabilized with $0,5,10$ and $15 \% \mathrm{CKD}$ in 2008 was selected to determine the field's electrical resistivity. The slope is located west of the New Mexico Institute of Mining and Technology $(34.080056,106.917583)$ in Socorro, NM, United States. Figure 1 presents the slope location.

The slope with about $64 \mathrm{~m}^{2}$ area and angle of 23 degrees divided into four sections and stabilized with 0, 5, 10 and $15 \%$ of Cement Kiln Dust to a depth of $30 \mathrm{~cm}$ respectively from left to right Fig. 2 to determine the soil's geotechnical properties. A series of $\mathrm{pH}$ tests were performed to prove CKD's existence on the slope after more than eleven years. $\mathrm{pH}$ tests were done according to (ASTM, 2019b); samples were taken from the slope surface and depths of 15 and $30 \mathrm{~cm}$ in each section with a spacing of $2 \mathrm{~m}$ in the $\mathrm{X}$ and $\mathrm{Y}$ directions.

For measuring the electrical resistivity of the slope, the 4-point Wenner method was followed per ASTM G57. Electrical resistivity sounding measurements involve placing four electrodes (stainless steel probes) in a straight line. A current is injected into the outer two probes and the potential difference is measured across the inner two probes. The resistance is calculated from the known current and the measured voltage. Seven resistivities sounding was measured for each section with a spacing of $1 \mathrm{~m}$ between the resistivity lines and $0.3 \mathrm{~m}$ between the electrodes from the slope's toe to the portion top Fig. 3. An analog resistivity meter called Humboldt $\mathrm{H} 4385$ with a resistant measurement range from $0.01 \Omega$ to $1.1 \mathrm{M} \Omega$. A potential of $12 \mathrm{~V}$ (Root Mean Square or RMS) crystal-controlled $97 \mathrm{~Hz}$ square wave oscillator was used to measure the slope's electrical resistivity. Figure 4 presents the schematic electrical resistivity measurements of the slope on the field. The electrical resistivity of slope computed by using the following equation:

$\rho=2 \pi S R$ 
Where:

$\rho=$ The resistivity of the materials $(\Omega-\mathrm{m})$

$R=$ The resistance obtained from the tester $(\Omega)$

$\pi=$ The constant $(\approx 3.1416)$

$S=$ Electrodes spacing $(\mathrm{m})$

\section{Laboratory Electrical Resistivity Measurement}

A series of laboratory tests were conducted to evaluate CKD's effect, water content, porosity and curing time on soil's electrical resistivity. The soil sample was taken from the untreated part of the slope at a depth of $30 \mathrm{~cm}$. The grain size distribution per ASTM D-422-63, moisture content per (ASTM, 2019a), unit weight per (ASTM, 2018), atterberg limits per (ASTM, 2017) and specific gravity per (ASTM, 2014) were conducted on the soil samples to estimate the soil physical properties. The pure soil and soil CKD mixed electrical resistivity was measured using the four-electrode probe method and a test apparatus called Humboldt analog resistivity meter using a Miler soil box Fig. 5. For this test, four electrodes have been used, an integral part of the electrolyte box. The electric frequency of the test apparatus was the same as the field measurements. To measure the electrical resistivity of samples, the (ASTM, 2020) was followed. The samples were dried to constant mass in an oven to follow the ASTM standard and then cooled at room temperature. The samples were passed through sieve number 10 to obtain $1300 \mathrm{~g}$ of passing. The samples were treated with 0 , 5,10 and $15 \%$ of CKD by dry weight of the soil and the electrical resistivity of samples was determined through different water content and curing time. Each test was identified for the specific CKD content, water content and curing period. Figure 5 illustrates the schematic electrical resistivity measurement in the laboratory. The soil resistivity of samples in the laboratory is computed using the following relation:

$\rho=R A / L$

Where:

$\rho=$ The resistivity of the materials $(\Omega-\mathrm{m})$

$R=$ The resistance obtained from the tester $(\Omega)$

$A=$ The cross-sectional area of the current electrodes $\left(\mathrm{cm}^{2}\right)$

$S=$ Electrodes spacing $(\mathrm{m})$

$L=$ The separation between the potential electrodes $(\mathrm{cm})$

During the laboratory test, the sample's porosity was determined based on the void ratio to evaluate the efficiency of Archie's law for this application. In this study, a simple regression analysis was adopted to analyze and correlate results using the least-squares regression method. Also, the slope soil corrosivity potential is discussed.

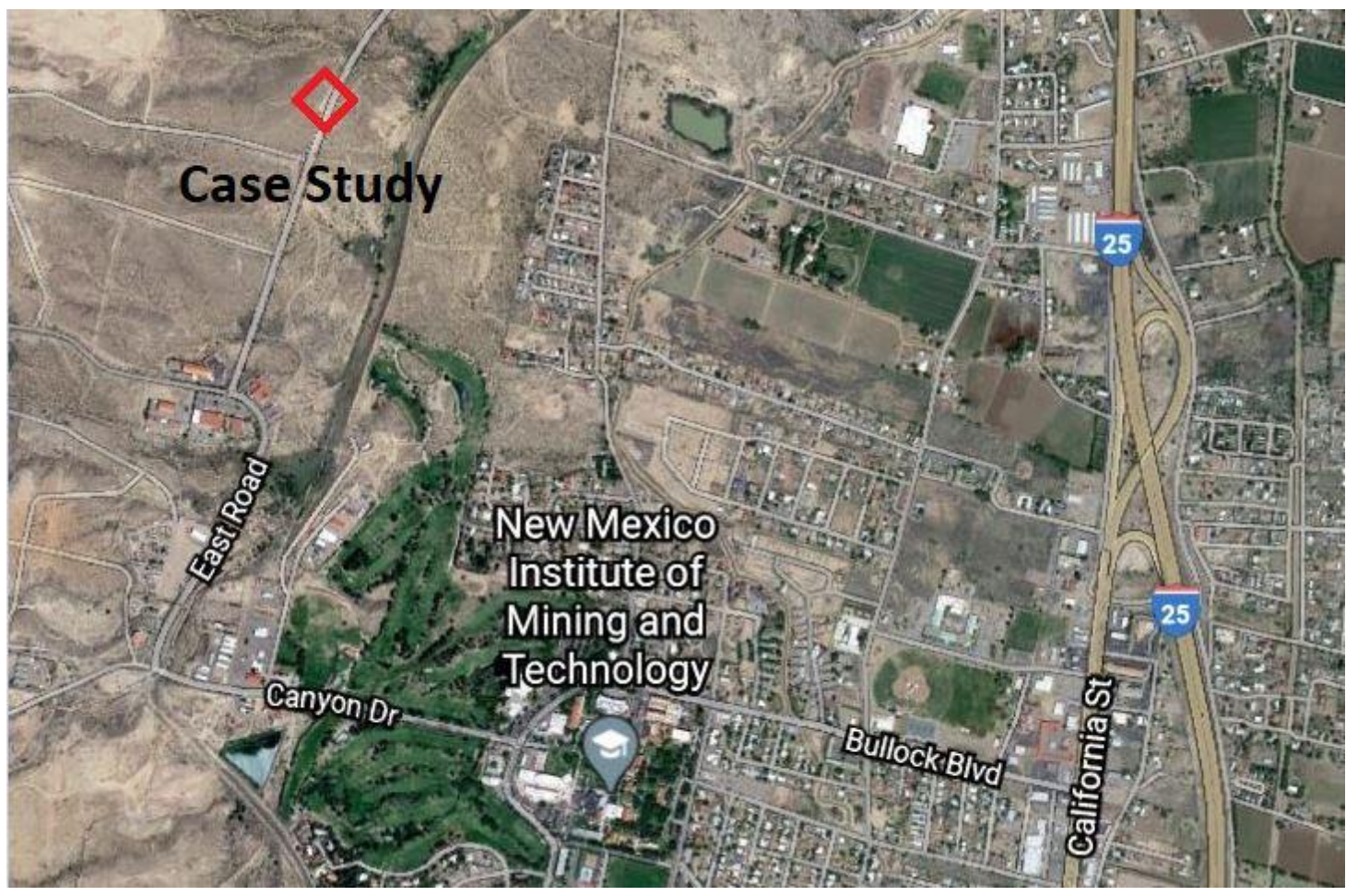

Fig. 1: Slope location (source: google earth) 


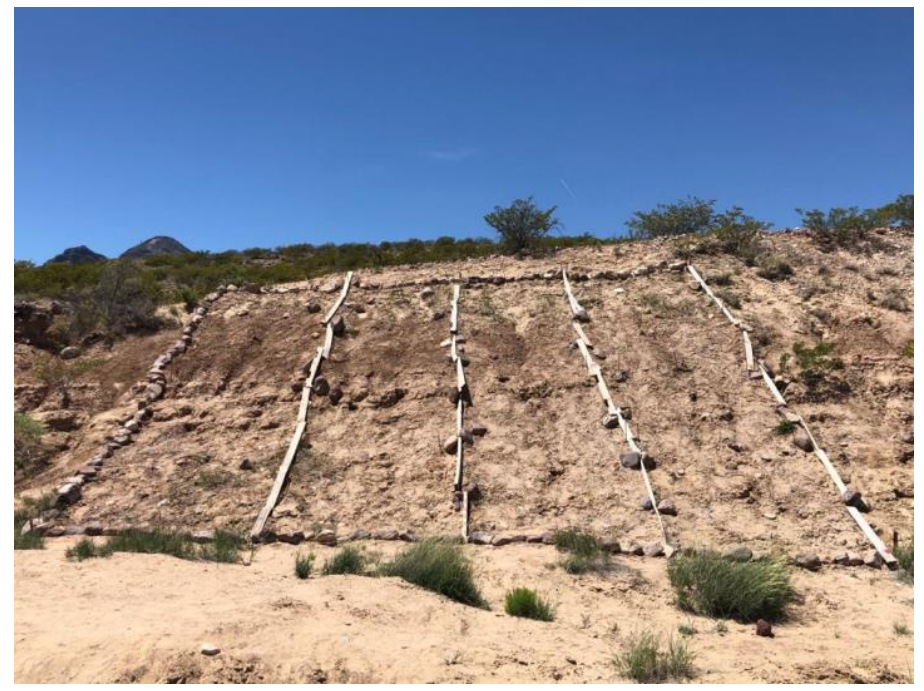

Fig. 2: Natural slope used for investigation after 11 years of treatment

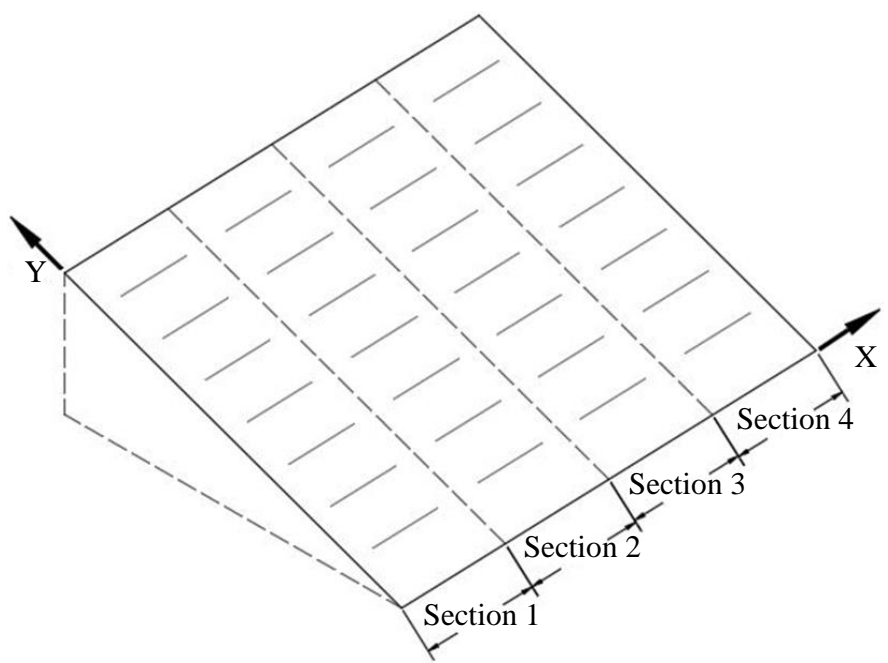

Fig. 3: Schematic of resistivity sounding lines on the slope

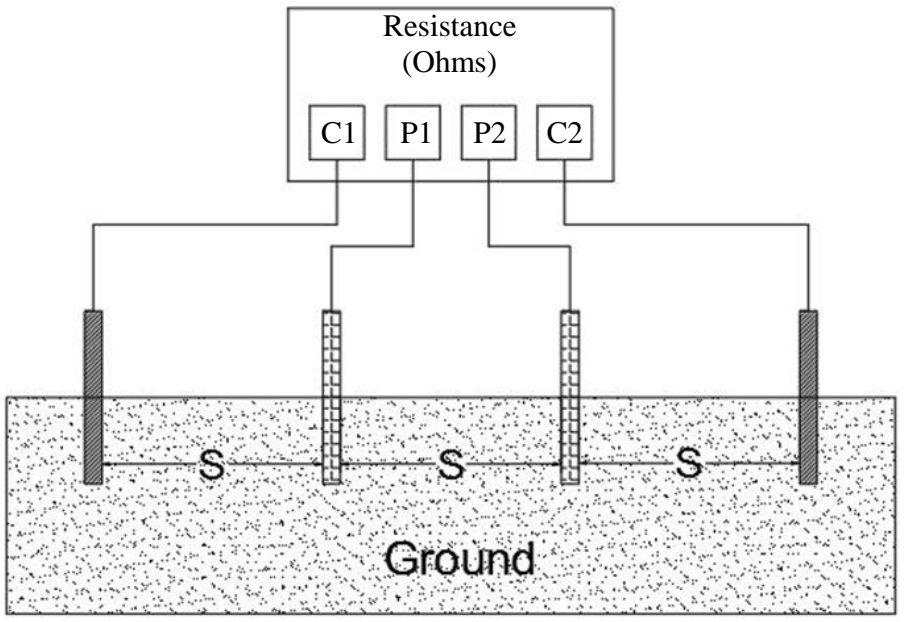

Fig. 4: Schematic of the four-electrode probe method for field measurements 


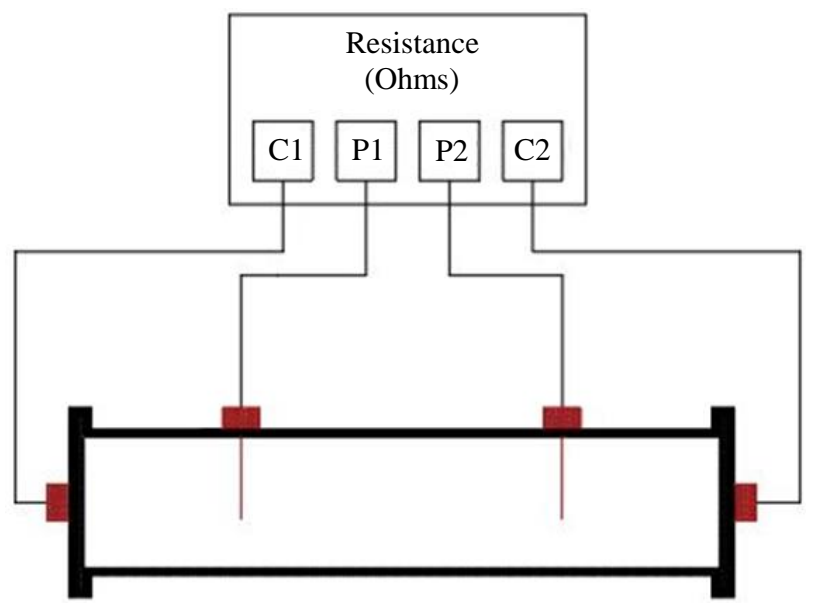

Fig. 5: A schematic drawing of the laboratory resistivity measurement instrument

\section{Results and Discussion}

\section{Materials Properties}

Engineering properties of the soil sample are summarized in Table 1. Figure 6 represents the particle size analysis of the soil sample according to (ASTM, 2007). The soil is classified as SM-SC according to the USCS classification. The natural water content of slope soil is measured as $2.5 \%$.

The present CKD content of the soil was traced using the correlation between the soil $\mathrm{pH}$ and CKD content. Figure 7 presents the soil $\mathrm{pH}$ at different CKD content. The soil $\mathrm{pH}$ was measured by sampling through all sections from the surface to the depth of $30 \mathrm{~cm}$. Figure 8 shows the CKD distribution based on $\mathrm{pH}$ measurements from the slope surface to $30 \mathrm{~cm}$ depth. It can be observed from the graph; there is a sign of CKD percent at the toe of the slope in section 1, which stabilized with no CKD. The $\mathrm{pH}$ results indicate the CKD existence on the slope from section 2 to section 4, almost with the same treatment pattern in 2008. The $\mathrm{pH}$ is changing for different locations, but it shows the CKD presence until $30 \mathrm{~cm}$ depth from section 2 to 4 with more concentration at $15 \mathrm{~cm}$ depth. The $\mathrm{pH}$ at the toe is more than the top of the slope. Besides, $\mathrm{pH}$ is increasing from section 2 to 4 by increasing the CKD content. The $30 \mathrm{~cm}$ depth is the boundary of treated soil with native soil and due to the settlement and error in measuring and sampling, the soil $\mathrm{pH}$ at 15 $\mathrm{cm}$ depth is more than $30 \mathrm{~cm}$ depth.

\section{Field Electrical Resistivity}

Twenty-eight sounding lines of electrical resistivity measurement were conducted at different sections to evaluate the slope electrical resistivity. Each unit includes seven sounding lines to determine the effect of different CKD amounts on soil electrical resistivity. The CKD was examined to a depth of $30 \mathrm{~cm}$ with different content of $0,5,10$ and $15 \%$, respectively, from left to right. The field electrical resistivity results conducted at different sections are presented in Table 2.

From the results, it is clear that electrical resistivity is increased as CKD content increases and section 4, which stabilized with $15 \%$ of CKD, shows the higher resistivity from the other sections. The electrical resistivity results for each section indicate that electrical resistivity for the same material is close. The mean of all line's electrical resistivity in each section is calculated as the final electrical resistivity for that section to compare with laboratory results. The first two lines' electrical resistivity in section 1 is not close to other lines due to CKD's presence at the toe of the slope in this section, proven by $\mathrm{pH}$ results. Consequently, to make an average and find the mean value for section 1, the first two lines' resistivity results are not considered further. Standard deviation is calculated for each section to measure how the resistivity results spread out in each section. A low standard deviation for each section's electrical resistivity indicates that the data points tend to be very close to the mean.

\section{Laboratory Electrical Resistivity}

\section{Effect of CKD Content on the Electrical Resistivity}

The relationship between the CKD content $(0,5,10$ and $15 \%$ ) and electrical resistivity for the CKD treated soil for different moisture contents of 2.5, 5.0, 7.5, 10.0, $12.5,15.0,17.5,20,22.5$ and $25 \%$ is determined and presented in Figs. 9 and 10. The results show that the electrical resistivity increases as CKD content increases, keeping moisture content constant. Mixing CKD with the soil causes a more incredible hydration reaction showing a higher electrical resistivity, so it is expected to record more electrical resistivity for higher CKD contents. Due to the hydration reaction between soil and $\mathrm{CKD}$, the water content and void ratio of soil-CKD admixture will be decreased. In this model, the electrical resistivity depends on three factors: Soil type, CKD and pore water. Among all these factors, the effect of water on electrical resistivity is more than the other parameters. 
Hamid Ranjkesh Adarmanabadi et al. / American Journal of Engineering and Applied Sciences 2021, 14 (1): 51.63 DOI: 10.3844/ajeassp.2021.51.63

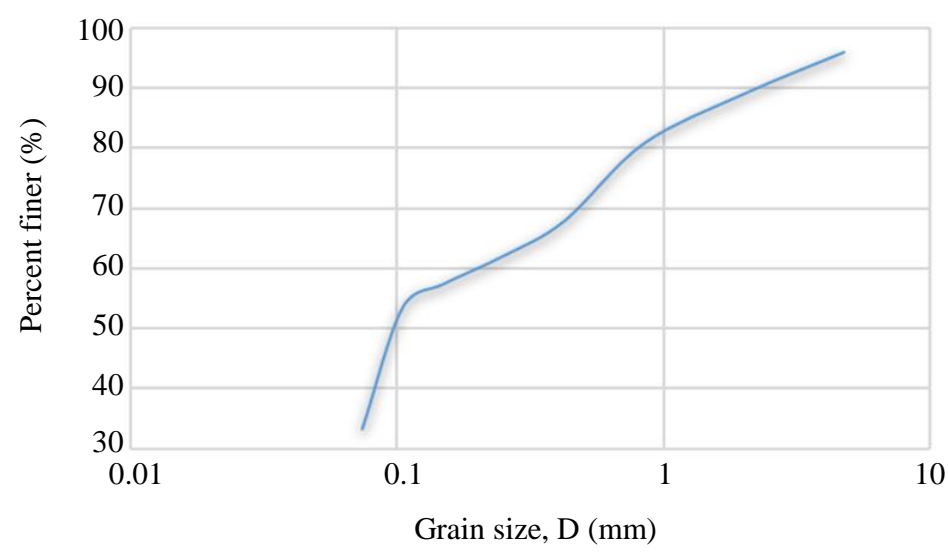

Fig. 6: Particle size distribution curve

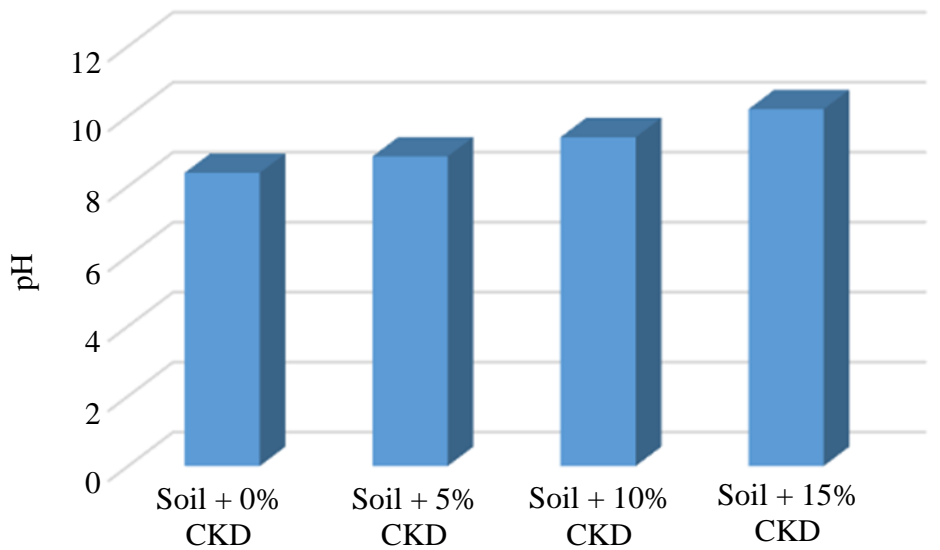

Fig. 7: Soil's pH at different CKD content

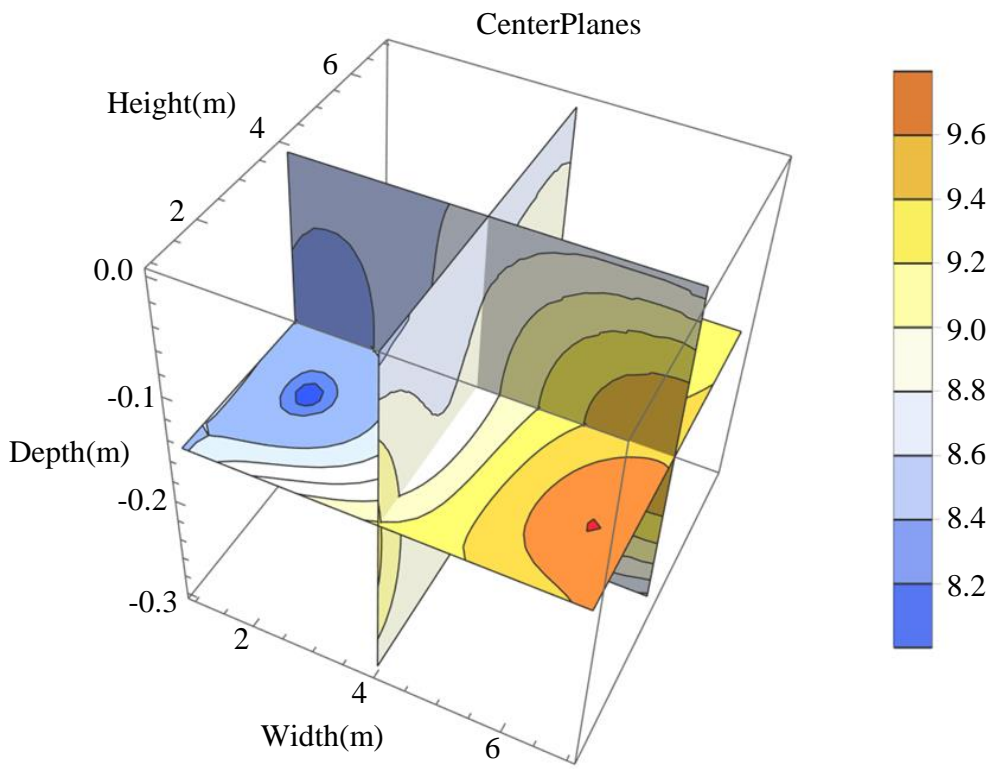

Fig. 8: 3D plot of CKD distribution based on $\mathrm{pH}$ measurements 


\section{Correlation Between Field and Laboratory Electrical Resistivity}

The electrical resistivity results from field and laboratory are analyzed to determine the similarities. The field electrical resistivity of the slope was measured at a water content of $2.5 \%$ and then compared with the laboratory results for the same water content. Figure 11 presents the field and laboratory's electrical resistivity for the same water content and a linear correlation is evaluated. The results indicate that the field and laboratory outcomes are similar and by increasing the CKD content, the soil electrical resistivity will be increased. The calculated correlation coefficient is 0.99 , indicating that the laboratory and field results are in good agreement. It signifies that the results obtained from the lab and field have a perfect positive relationship. Electrical resistivity results in the lab and electrical resistivity in the field are positively correlated besides. This conclusion is verified in Fig. 11. There is a difference between laboratory and field results, which may happen because of long-term curing of CKD or depth and a small change in water content.

\section{Effect of Water Content on the Electrical Resistivity}

Some soil properties such as water content (water quality and quantity) affect the soil's electrical resistivity. Figure 12 shows the effect of water content on the electrical resistivity of the native soil and soil CKD mixtures with different CKD contents. The data show a reduction in electrical resistivity by increasing water content. The results for natural soil and soil treated with different amounts of CKD follow the same pattern of decline in electrical resistivity with an increase in moisture content. The electrical resistivity decreased rapidly for water content less than $15 \%$ and electrical resistivity reduction is getting less for water content more than $15 \%$. (Komine, 1997) evaluated the electrical resistivity of soil, soil cement admixture and pore water, suggesting a model that indicates pore water's effect on the electrical resistivity was most significant compared to the other factors.

\section{Effect of Porosity on the Electrical Resistivity}

Soil void ratio and porosity are determined using Eqs. 3 and 4 to evaluate the effect of porosity on the electrical resistivity of the native soil and the soil treated with CKD. Besides, the accuracy of Archie's law is evaluated:

$e=(((1+\omega) G s \gamma w) / \gamma)-1$

$n=e /(1+e)$

\author{
Where: \\ $n$ = Porosity \\ $e=$ A void ratio \\ $\omega=$ Water content \\ $\gamma=$ The unit weight $\left(\mathrm{kN} / \mathrm{m}^{3}\right)$ \\ $G s=$ The specific gravity \\ $\gamma_{w}=$ The unit weight of water $\left(\mathrm{kN} / \mathrm{m}^{3}\right)$
}

CKD in the soil causes an increase in the soil's specific gravity and soil bulk density. CKD particles are very fine, so CKD acts like a filler, which reduces the void spacings or a decrease in soil porosity. The CKD treated soil specimens' initial porosities were determined at different water contents of $2.5,7.5$ and $12.5 \%$ at the mixing time. The soil porosity decreased as curing time due to hydration process development and bonding the soil particles with chemical materials. Figure 13 shows the electrical resistivity results as a function of the initial porosity. It can be concluded that the porosity has a significant effect on the electrical resistivity of soil treated with CKD, which shows the same pattern of Archie's law. However, Archie's law was for untreated saturated soil. The behavior of soil electrical resistivity as a function of porosity was reported by other researchers (Archie, 1942). These chemical products which cause by mixing CKD to the soil, filled in the pore space and bonded with solid particles to make a denser structure and thus reduced the porosity and increase the electric current, which is consistent with the results of literature (Liu et al., 2009; Chen et al., 2011).

\section{Effect of Curing Time on the Electrical Resistivity}

Figures 14 to 16 present the relationship between curing time and soil CKD mixture's electrical resistivity for different soil-CKD ratios. The soil electrical resistivity is measured at different water-CKD rates of $0.5,1.5$ and $2.5 \%$ for $1,7,14,21$ and 28 days curing for various CKD content soil admixtures under controlled conditions. The following graphs present the electrical resistivity versus curing time for soil mixed with 5, 10 and $15 \%$ of CKD by the soil's dry weight. The results prove an increase in electrical resistivity by increasing curing periods and CKD content. The pozzolanic reactions cause a decrease in water content and an increase in electrical resistivity by increasing the curing time (Horpibulsuk et al., 2003). Furthermore, the researchers indicate by increasing the curing time; contents of chemical reaction productions such as Calcium Silicate Hydrate (CSH) and Calcium Aluminate Hydrate (CAH) formed and lead more tortuous pathways for the flow of electrical current in the soil-CKD mixture and cause to increase the electrical resistivity (Liu et al., 2008; Bergado et al., 1996). 


\section{Relation of Soil Unconfined Compression Strength and Electrical Resistivity}

The unconfined compression strength (UCS) test per (ASTM, 2006) was conducted for pure soil and stabilized soil with 5,10 and 15\% CKD (by the soil's dry weight) at curing times of $1,7,14,21$ and 28 days to evaluate the relation of electrical resistivity and unconfined compression strength. It was observed that soil particles, stabilizer agents, water content and curing time affect the soil resistivity and unconfined compression strength. Therefore, it should relate the soil electrical resistivity and unconfined compression strength (Horpibulsuk et al., 2003). The unconfined compression strength increased with rising CKD content and curing time. Figure 17 displays the results of the unconfined compression strength of laboratory tests versus the electrical resistivity measured. It can be seen that there is a linear relation between unconfined compression strength and electrical resistivity. As strength increases, the electrical resistivity will rise.

\section{Soil Corrosivity}

Soil corrosivity is soil potential to buried metals and concrete that is in direct contact with soil. Acidic or alkaline soils and organic soils can be corrosive. Moisture and oxygen are two essential factors for the corrosion process and above the groundwater level, the corrosion rate is greater. Some soil properties, including soil resistivity, soil $\mathrm{pH}$, soluble salt content, moisture content and drainage conditions, affect soil corrosivity (Sadiq et al., 2004). Several classification systems are available to rate the soil corrosion potential. Table 3 presents a corrosivity score based on the soil resistivity, soil $\mathrm{pH}$ and moisture content and Table 4 shows the soil corrosion potential based on the corrosivity score.

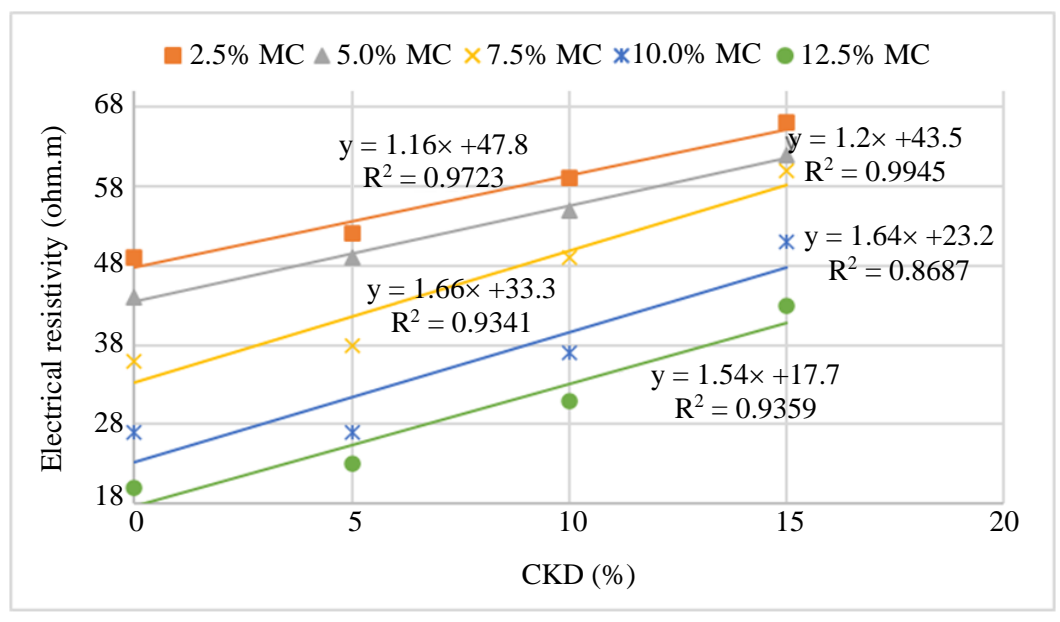

Fig. 9: Electrical resistivity versus CKD content for 2.5 to $12.5 \% \mathrm{MC}$

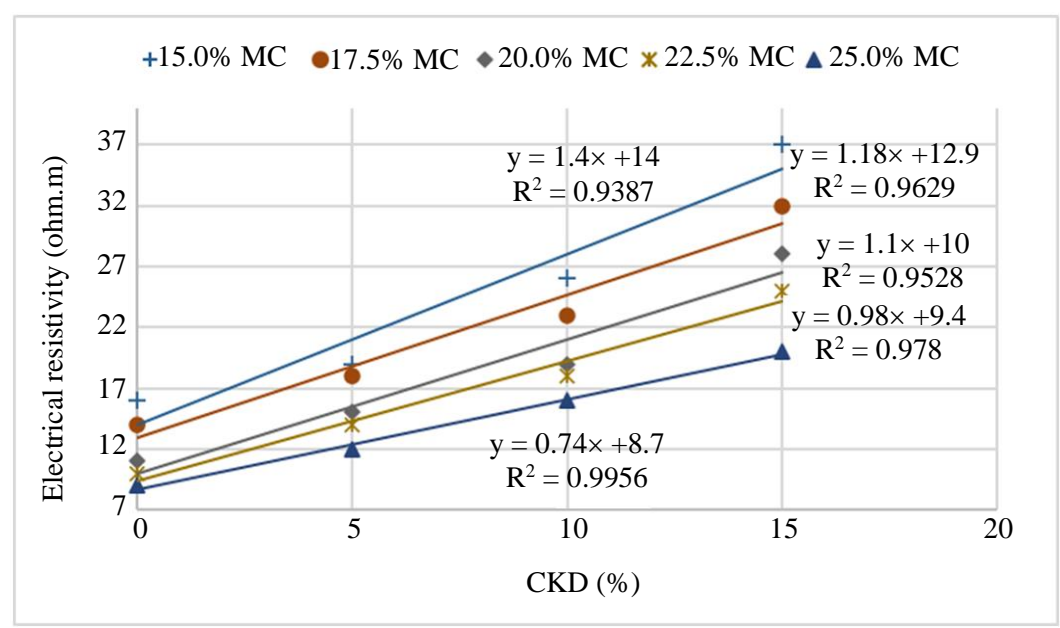

Fig. 10: Electrical resistivity versus CKD content for 15.0 to $25.0 \% \mathrm{MC}$ 
Hamid Ranjkesh Adarmanabadi et al. / American Journal of Engineering and Applied Sciences 2021, 14 (1): 51.63 DOI: 10.3844/ajeassp.2021.51.63

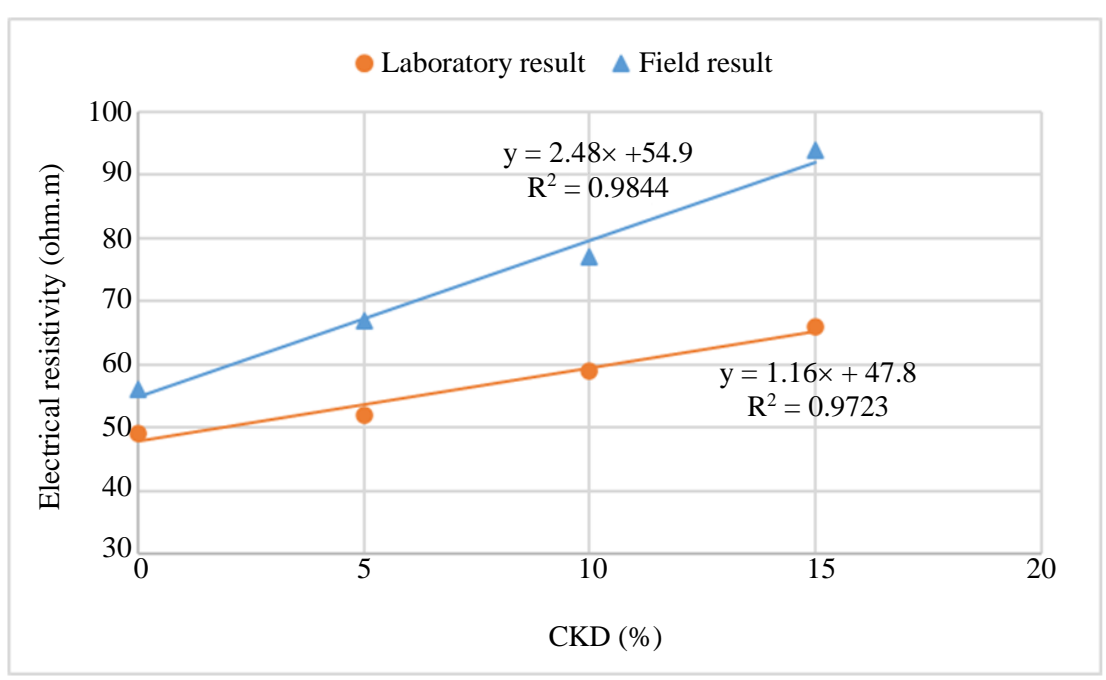

Fig. 11: Field and laboratory results for $2.5 \% \mathrm{MC}$

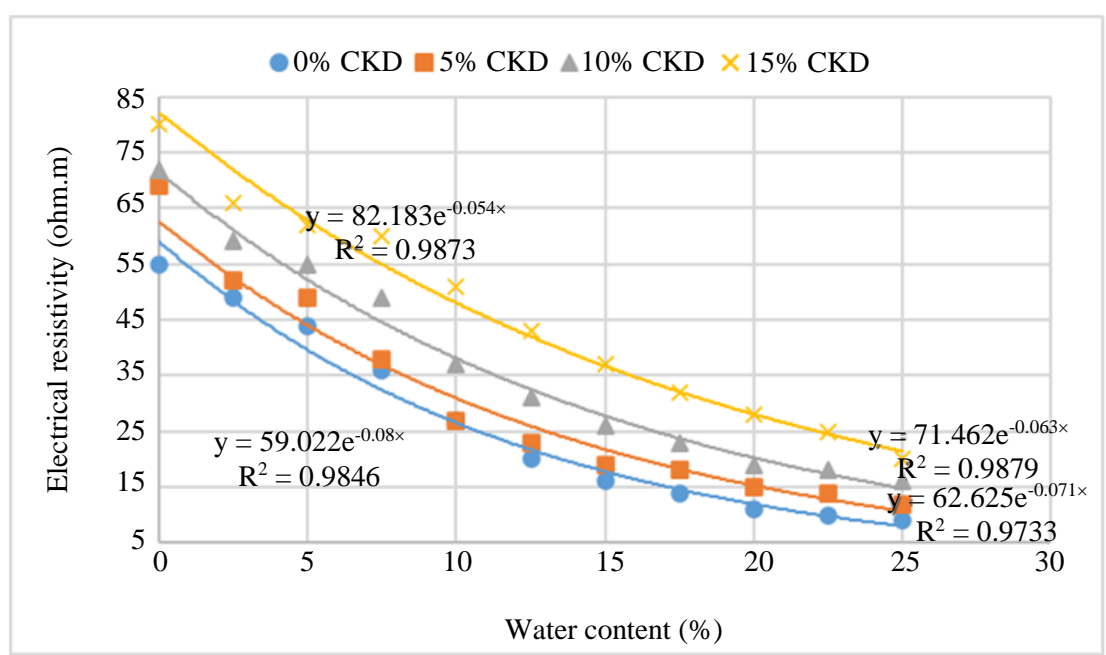

Fig. 12: Electrical resistivity versus water content

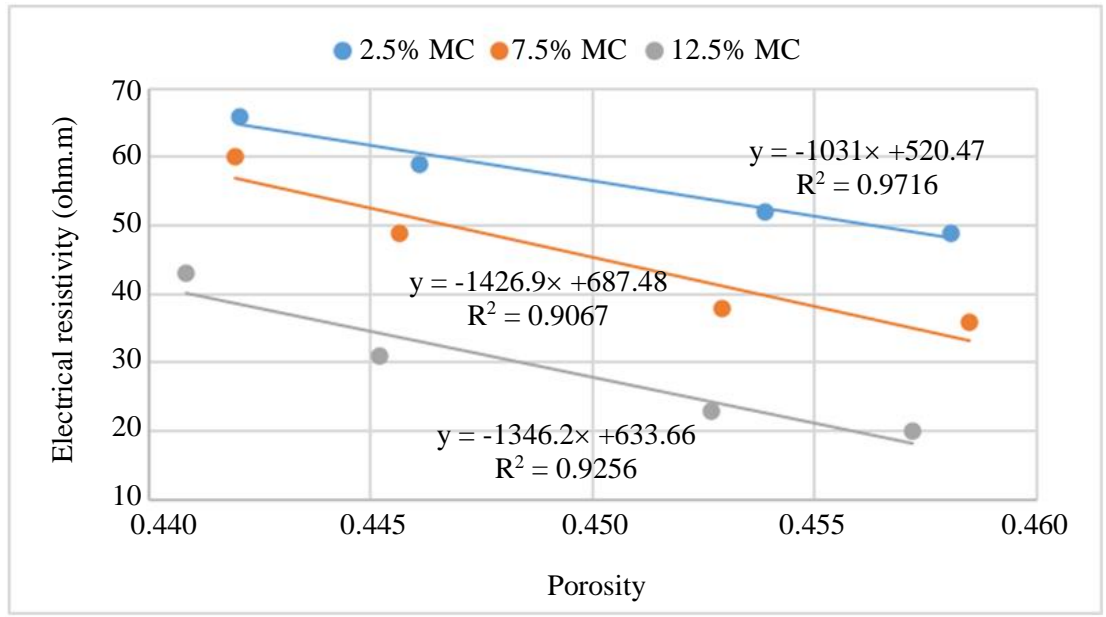

Fig. 13: Electrical resistivity versus porosity 
Hamid Ranjkesh Adarmanabadi et al. / American Journal of Engineering and Applied Sciences 2021, 14 (1): 51.63 DOI: 10.3844/ajeassp.2021.51.63

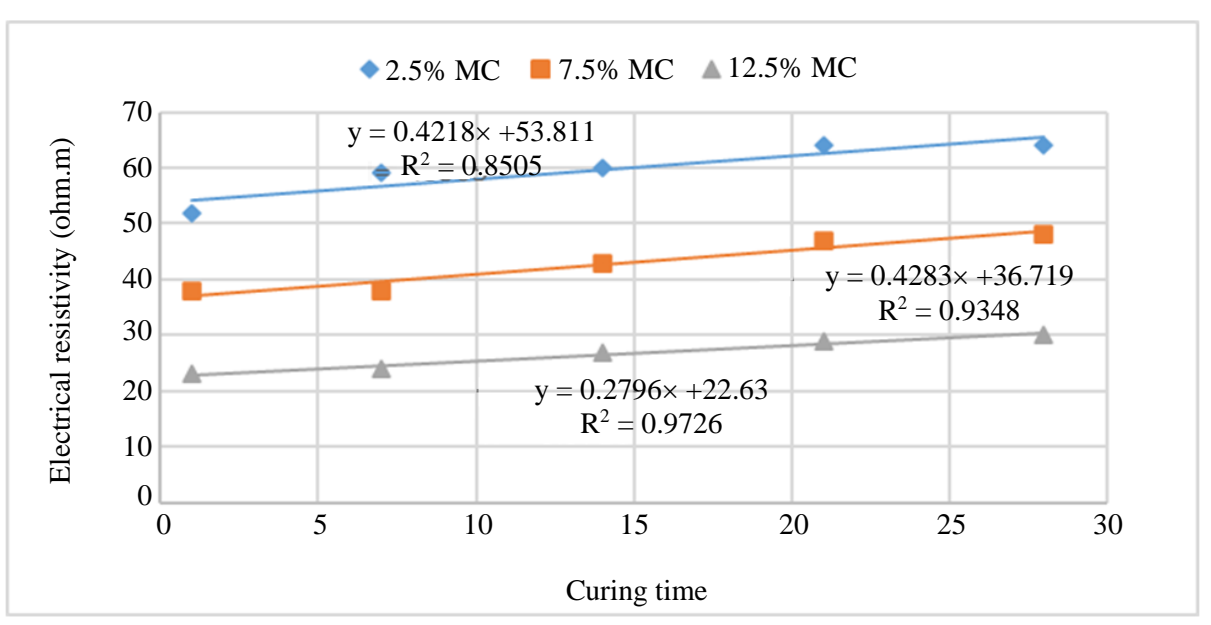

Fig. 14: Electrical resistivity versus curing time for soil $+5 \% \mathrm{CKD}$

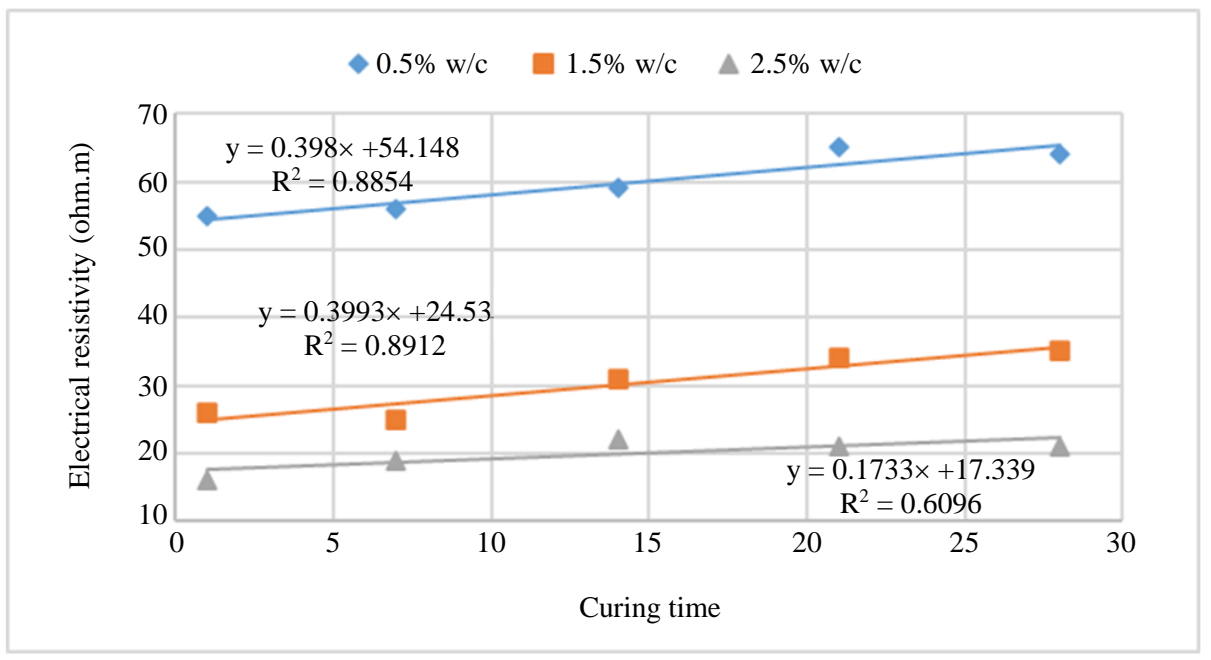

Fig. 15: Electrical resistivity versus curing time for soil $+10 \%$ CKD

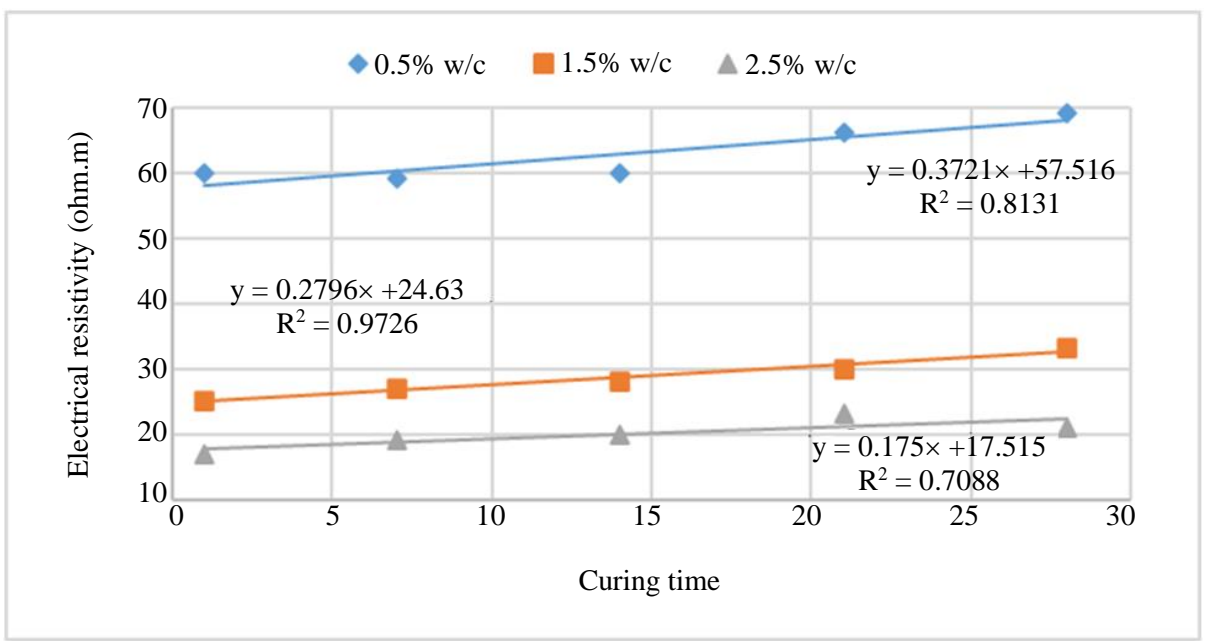

Fig. 16: Electrical resistivity versus curing time for soil $+15 \%$ CKD 


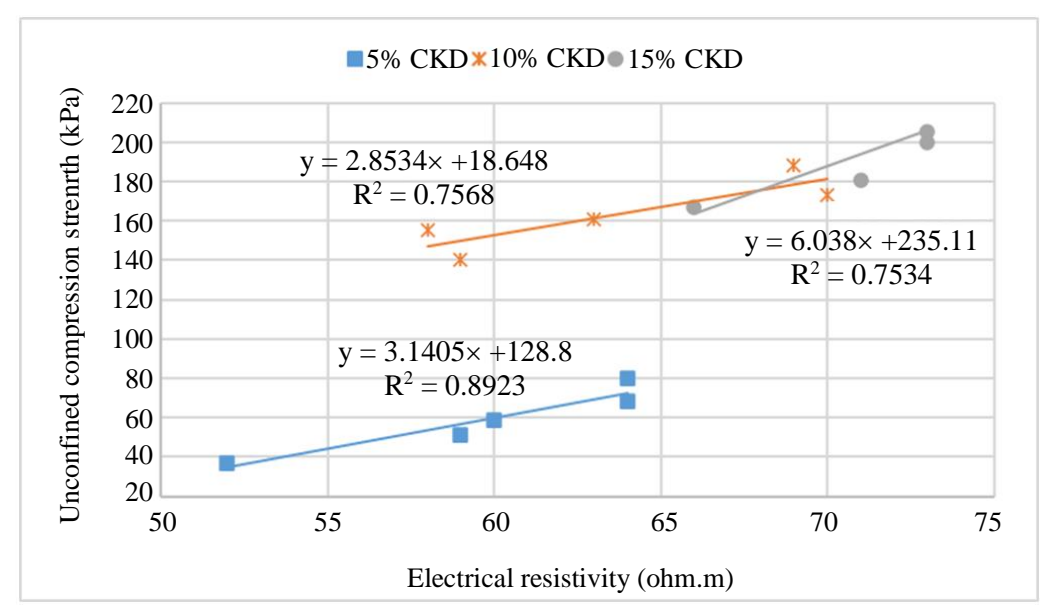

Fig. 17: Electrical resistivity versus UCS

Table 1: Physical properties of soil used for this study

\begin{tabular}{ll}
\hline Properties & Characteristics values \\
\hline USCS Symbol & SM-SC \\
Specific Gravity $G_{s}$ & 2.68 \\
Liquid Limit $w_{l}(\%)$ & - \\
Plastic Limit $w_{p}(\%)$ & - \\
Natural Water Content $\omega(\%)$ & 2.5 \\
Unit Weight $\gamma\left(\mathrm{kN} / \mathrm{m}^{3}\right)$ & 14.6 \\
\hline
\end{tabular}

Table 2: Field electrical resistivity results

\begin{tabular}{|c|c|c|c|c|}
\hline \multicolumn{5}{|c|}{ Field Electrical Resistivity Results $(\Omega-\mathrm{m})$} \\
\hline \multicolumn{5}{|c|}{ Sounding Line $\quad$ Section $1(0 \% \mathrm{CKD})$} \\
\hline$\overline{1}$ & 66.00 & 70.00 & 81.00 & 99.0 \\
\hline 2 & 67.00 & 68.00 & 79.00 & 95.0 \\
\hline 3 & 59.00 & 62.00 & 76.00 & 92.0 \\
\hline 4 & 58.00 & 66.00 & 77.00 & 92.0 \\
\hline 5 & 54.00 & 68.00 & 73.00 & 94.0 \\
\hline 6 & 56.00 & 71.00 & 77.00 & 96.0 \\
\hline 7 & 55.00 & 65.00 & 74.00 & 89.0 \\
\hline Mean & 56.40 & 67.10 & 76.70 & 93.8 \\
\hline Standard deviation & 2.07 & 3.08 & 2.75 & 3.2 \\
\hline
\end{tabular}

Table 3: Typical numerical corrosivity scoring system (Clayton, 2013)

\begin{tabular}{lll}
\hline Soil parameter & Value & Score \\
\hline Resistivity $(\Omega-\mathrm{m})$ & $<5$ & 10 \\
& 5 to 9.99 & 8 \\
& 10 to 19.9 & 5 \\
& 20 to 49.9 & 2 \\
& 50 to 100 & 1 \\
& $>100$ & 0 \\
$\mathrm{pH}$ & 2 to 4.5 & 6 \\
& 5 to 6 & 0 \\
& 7 to 9 & 6 \\
Moisture & 10.5 to 12 & 2 \\
& Tidal or Salt Water & 5 \\
& Poor Drainage-Always Wet & 2 \\
& Fair Drainage-Moist & 1 \\
& Good Drainage-Usually Dry & 0 \\
\hline
\end{tabular}

Table 4: Soil corrosion potential (Clayton, 2013)

\begin{tabular}{ll}
\hline Total Corrosivity Score & Soil Corrosion Potential \\
\hline 0 to 2 & Unlikely \\
3 to 4 & Slight \\
5 to 6 & Mild \\
7 to 8 & Moderate \\
9 to 13 & Aggressive \\
14 to 20 & Severe \\
\hline
\end{tabular}

Table 5: Slope soil corrosion potential

\begin{tabular}{llll}
\hline Section & CKD content & Score & Soil corrosion potential \\
\hline 1 & 0 & 8 & Moderate \\
2 & 5 & 7 & Moderate \\
3 & 10 & 7 & Moderate \\
4 & 15 & 7 & Moderate \\
\hline
\end{tabular}


Table 5 present the soil corrosion potential of slope for the different sections with different amounts of CKD. The results indicate that all sections' soil corrosion potential is almost the same and CKD can decrease the soil corrosion potential for a small amount.

\section{Conclusion}

The effects of different parameters on the CKD treated soil electrical resistivity were studied both in the lab and field. The relationship between the measured electrical resistivity with soil $\mathrm{pH}, \mathrm{CKD}$ content, water content, porosity, curing time and soil corrosion potential were investigated. CKD increases soil $\mathrm{pH}$ and electrical resistivity. The electrical resistivity of the CKD treated soil increases by increasing the CKD content and the curing time. However, the soil's electrical resistivity and the CKD treated soil decrease with increasing the water content and porosity. Field and laboratory results indicate that the water content is a significant parameter affecting the electrical resistivity. Additionally, soil electrical resistivity, soil $\mathrm{pH}$ and soil moisture content are essential parameters to evaluate the soil corrosion potential and soil corrosion potential decreases by increasing the CKD content. It can be concluded that electrical resistivity is a significant parameter to evaluate the soil's geotechnical properties.

\section{Funding Information}

This research was funded by the Mineral engineering department of the New Mexico Institute of Mining and Technology. The authors gratefully acknowledge the support of the mineral engineering department.

\section{Author's Contributions}

Hamid Ranjkesh Adarmanabadi: Contributed to idea development and design the study, performing the experiments, data preparation and analysis and writing the manuscript.

Arezou Rasti: Contributed to design the study, performing the test, data analysis and writing the manuscript.

Mehrdad Razavi: Contributed to idea development analyzed the experiments results and review the manuscript.

\section{Ethics}

This article is original and contains unpublished materials. The authors have read and approved this manuscript and no ethical issues are involved.

\section{References}

Abu-Hassanein, Z. S., Benson, C. H., \& Blotz, L. R. (1996). Electrical resistivity of compacted clays. Journal of geotechnical engineering, 122(5), 397-406.

Archie, G. E. (1942). The electrical resistivity log as an aid in determining some reservoir characteristics. Transactions of the AIME, 146(01), 54-62.

ASTM, D. (2006). Standard test method for unconfined compressive strength of cohesive soil. ASTM standard D, 2166.

ASTM. (2007). Standard Test Method for Particle-Size Analysis of Soils (Withdrawn 2016), ASTM International, West Conshohocken, PA.

ASTM. (2014). Standard Test Methods for Specific Gravity of Soil Solids by Water Pycnometer, ASTM International, West Conshohocken, PA.

ASTM. (2017). Standard Test Methods for Liquid Limit, Plastic Limit and Plasticity Index of Soils, ASTM International, West Conshohocken, PA.

ASTM. (2018). Standard Test Methods for Laboratory Determination of Density (Unit Weight) of Soil Specimens, ASTM International, West Conshohocken, PA.

ASTM. (2019a). Standard Test Methods for Laboratory Determination of Water (Moisture) Content of Soil and Rock by Mass, ASTM International, West Conshohocken, PA, 2019.

ASTM. (2019b). ASTM D4972-19, Standard Test Methods for $\mathrm{pH}$ of Soils. American Society for Testing and Materials.

ASTM. (2020). Standard Test Method for Measurement of Soil Resistivity Using the Wenner Four-Electrode Method, ASTM International, West Conshohocken, PA.

Baghdadi, Z. A., Fatani, M. N., \& Sabban, N. A. (1995). Soil modification by cement kiln dust. Journal of Materials in Civil Engineering, 7(4), 218-222.

Bergado, D. T., Anderson, L. R., Miura, N., \& Balasubramaniam, A. S. (1996, January). Soft ground improvement in lowland and other environments. AsCE.

Cai, G. H., Du, Y. J., Liu, S. Y., \& Singh, D. N. (2015). Physical properties, electrical resistivity and strength characteristics of carbonated silty soil admixed with reactive magnesia. Canadian Geotechnical Journal, 52(11), 1699-1713.

Chen, L., Du, Y. J., Liu, S. Y., \& Jin, F. (2011). Evaluation of cement hydration properties of cement-stabilized lead-contaminated soils using electrical resistivity measurement. Journal of Hazardous, Toxic and Radioactive Waste, 15(4), 312-320.

Clayton, D. J. (2013). ECP Design \& Technical Service Manual. Earth Contact Products, LLC, 9: 120-130. https://www.earthcontactproducts.com/wpcontent/uploads/all/ECP-2013-Tech-Manual.pdf. 
Damasceno, V. M., Fratta, D., \& Bosscher, P. J. (2009). Development and validation of a low-cost electrical resistivity tomographer for soil process monitoring. Canadian Geotechnical Journal, 46(7), 842-854.

Faramarzi, L., Rasti, A., \& Abtahi, S. M. (2016). An experimental study of the effect of cement and chemical grouting on the improvement of the mechanical and hydraulic properties of alluvial formations. Construction and Building Materials, 126, 32-43.

Ghazvinian, B., \& Razavi, M. (2010). Stabilization and Erosion Control of Slopes using Cement Kiln Dust. In GeoFlorida 2010: Advances in Analysis, Modeling \& Design (pp. 2454-2461).

Horpibulsuk, S., Miura, N., \& Nagaraj, T. S. (2003). Assessment of strength development in cementadmixed high water content clays with Abrams' law as a basis. Geotechnique, 53(4), 439-444.

Kalinski, R. J., \& Kelly, W. E. (1993). Estimating water content of soils from electrical resistivity. Geotechnical Testing Journal, 16(3), 323-329.

Komine, H. (1997). Evaluation of chemical grouted soil by electrical resistivity. Proceedings of the Institution of Civil Engineers-Ground Improvement, 1(2), 101-113.

Liao, Y., Shen, Q., Xu, P., Liao, G., \& Zhong, X. (2019). Effect of Fly Ash on the Electrical Resistivity of Cement-based Materials During the Hydration Process. Materials Reports, (8), 18.

Liu, J., Zha, F., Xu, L., Kang, B., Tan, X., Deng, Y., \& Yang, C. (2019). Mechanism of stabilized/solidified heavy metal contaminated soils with cement-fly ash based on electrical resistivity measurements. Measurement, 141, 85-94.

Liu, S. Y., Du, Y. J., Han, L. H., \& Gu, M. F. (2008). Experimental study on the electrical resistivity of soil-cement admixtures. Environmental Geology, 54(6), 1227-1233.
Liu, S., Zhang, D., \& Zhu, Z. (2009). On the uniformity of deep mixed soil-cement columns with electrical resistivity method. In Advances in Ground Improvement: Research to Practice in the United States and China (pp. 140-149).

Ranjkesh Adarmanabadi, H., A. Rasti and M. Razavi. (2020). Thermal image analysis of a cement kiln dust treated slope. International Journal of Science and Engineering Investigations (IJSEI), 9 (107): 29 36. http://www.ijsei.com/papers/ijsei-910720-05.pdf

Rinaldi, V. A., \& Cuestas, G. A. (2002). Ohmic conductivity of a compacted silty clay. Journal of Geotechnical and Geoenvironmental Engineering, 128(10), 824-835.

Rouhanifar, S., Afrazi, M., Fakhimi, A., \& Yazdani, M. (2020). Strength and deformation behaviour of sandrubber mixture. International Journal of Geotechnical Engineering, 1-15.

Sadiq, R., Rajani, B., \& Kleiner, Y. (2004). Fuzzy-based method to evaluate soil corrosivity for prediction of water main deterioration. Journal of infrastructure systems, 10(4), 149-156.

Samouëlian, A., Cousin, I., Tabbagh, A., Bruand, A., \& Richard, G. (2005). Electrical resistivity survey in soil science: a review. Soil and Tillage research, 83(2), 173-193.

Tabbagh, A., Dabas, M., Hesse, A., \& Panissod, C. (2000). Soil resistivity: a non-invasive tool to map soil structure horizonation. Geoderma, 97 (3-4), 393-404.

Zhang, D. W., Chen, L., \& Liu, S. Y. (2012). Key parameters controlling electrical resistivity and strength of cement treated soils. Journal of Central South University, 19(10), 2991-2998. 